\title{
VARIATIONS IN RADON CONCENTRATIONS IN THE UNDERGROUND WATERS DURING THE GENERATION AND OCCURRENCE OF SEISMIC EVENTS IN THE BAIKAL REGION
}

\begin{abstract}
A.K. Seminsky $\oplus^{凶}$
Institute of the Earth's Crust, Siberian Branch of the Russian Academy of Sciences, 128 Lermontov St, Irkutsk 664033, Russia

ABSTRACT. The purpose of this work is to analyze the variations of radon volumetric activity in groundwater from the South Angara region and to identify and study the response of the emanation field to the most significant seismic events that occurred in the Baikal region in 2021. To achieve this goal, we organized daily monitoring of the radioactivity of groundwater in the study area. The analysis of the obtained series made it possible to determine the amplitude of fluctuations of radon volumetric activity Q (from 13.2 to $48.4 \mathrm{~Bq} / \mathrm{L}$ ), as well as the average annual (26 Bq/L) and daily average $(4.5 \mathrm{~Bq} / \mathrm{L})$ indicators.

The total number of earthquakes that occurred during the year on the territory of the Baikal region yielded a sample of 40 most significant $(M \geq 4)$ events, for which the radii of the areas of influence were calculated. In three cases, we found that the sampling points were located within the influence radii or close to it. In four cases, the actual distances from the monitoring points to the epicentres were one and a half to three times greater than the calculated radii, and in the rest thirty-three cases, these distances were more than three times greater than that.

Three types of emanation responses to seismic events have been identified, with one of which to be recorded before an earthquake, that is, to be a prognostic sign. Among the earthquakes demonstrating this effect, the Khubsugul earthquake was the strongest in the study area over the past ten years. Grouping by distance from the source to the sampling point relative to the radius of the event's influence practically coincides with the set of earthquakes by the recording time and the type of recorded responses.

Thus, the fluctuations of the emanation field spread over considerable distances from the earthquake generation area with gradual attenuation, and the response recording moment and the type of anomaly that appeared on the graph depend on the power of an impending event, as well as on the distance between the earthquake epicentre and the sampling point. The study shows that the possibility of identifying the emanation precursor effects before strong earthquakes on the territory of the Baikal region is based on two primary conditions: first, sufficient strength of an impending earthquake; second, the location of the sampling point within the radius of the area of influence of this earthquake.
\end{abstract}

KEYWORDS: radon; underground waters; monitoring; earthquake; Baikal region

FUNDING: The study has been done as part of the budget-financed project "Recent geodynamics, mechanisms of lithospheric destruction and geological hazards in Central Asia №FWEF-2021-0009". The study used the equipment of the Geochronology Center for Collective Use, Institute of the Earth's Crust SB RAS, under the grant 075-15-2021-682.

\section{SHORT COMMUNICATION}

Correspondence: Alexander K. Seminsky, zzzsancheszzz@gmail.com
Received: December 6, 2021

Revised: December 22, 2021

Accepted: December 30, 2021

FOR CITATION: Seminsky A.K., 2022. Variations in radon concentrations in the underground waters during the generation and occurrence of seismic events in the Baikal region. Geodynamics \& Tectonophysics 13 (2s), 0631. doi:10.5800/GT-2022-13-2s-0631 


\title{
ВАРИАЦИИ РАДОНА В ПОДЗЕМНЫХ ВОДАХ ПРИ ПОДГОТОВКЕ И РЕАЛИЗАЦИИ СЕЙСМИЧЕСКИХ СОБЫТИЙ БАЙКАЛЬСКОГО РЕГИОНА
}

\author{
А.К. Семинский
}

Институт земной коры СО РАН, 664033, Иркутск, ул. Лермонтова, 128, Россия

АНнотАЦИЯ. Цель работы - проанализировать вариации объемной активности радона в подземных водах Южного Приангарья, а также выявить и изучить отклик эманационного поля на наиболее крупные сейсмические события, произошедшие на территории Байкальского региона в 2021 г. Для достижения намеченной цели организован ежедневный мониторинг радиоактивности подземных вод исследуемой территории. Анализ полученных рядов позволил установить амплитуду флуктуаций объемной активности радона (Q) (от 13.2 до 48.4 Бк/л), а также среднегодовой (26 Бк/л) и среднесуточный (4.5 Бк/л) показатели.

Из числа землетрясений, произошедших в течение года на территории Байкальского региона, создана выборка, включающая 40 наиболее значимых $(\mathrm{M} \geq 4)$ событий, для которых рассчитывались радиусы областей влияния. Установлено, что в трех случаях пункт опробования располагался в пределах радиуса влияния или находился от него в непосредственной близости, в четырех случаях фактическая дистанция от пункта мониторинга до эпицентра в полтора-три раза превышала расчетный радиус, в оставшихся тридцати трех случаях это расстояние было превышено более чем в три раза.

Выявлено три типа эманационного отклика на сейсмические события, один из которых может быть зафиксирован перед землетрясением, т.е. является прогностическим признаком. В число сейсмических событий, демонстрирующих такой эффект, вошло Хубсугульское землетрясение, являющееся наиболее сильным на территории исследования за последние десять лет. Группировка по удаленности очага от пункта опробования относительно радиуса влияния произошедшего события практически совпадает с группировкой землетрясений по времени регистрации и типу фиксируемых откликов.

Таким образом, колебания эманационного поля распространяются от области подготовки землетрясения на значительные расстояния с постепенным затуханием, а момент фиксации отклика и вид проявившейся на графике аномалии зависят от мощности готовящегося события, а также от расстояния между эпицентром землетрясения и пунктом опробования. Проведенное исследование показывает, что выявление эманационных предвестниковых эффектов перед сильными землетрясениями на территории Байкальского региона возможно при удовлетворении двум главным условиям: во-первых, достаточной силе готовящегося землетрясения; во-вторых, расположению пункта опробования в пределах радиуса области влияния данного события.

КЛЮчЕВЫЕ СЛОВА: радон; подземные воды; мониторинг; землетрясение; Байкальский регион

ФИНАНСИРОВАНИЕ: Исследование проведено в рамках бюджетного проекта «Современная геодинамика, механизмы деструкции литосферы и опасные геологические процессы в Центральной Азии № FWEF-2021-0009». В работе задействовалось оборудование ЦКП «Геодинамика и геохронология» Института земной коры СО РАН в рамках гранта № 075-15-2021-682.

\section{1. ВВЕДЕНИЕ}

Изучение характеристических связей сейсмической активности с различными показателями окружающей среды является одним из наиболее активно развивающихся научных направлений. Из почти 500 научных работ, опубликованных в течение трех последних десятилетий, направленных на выявление откликов сейсмических событий, более 150 посвящены гидрогеологическим исследованиям, две трети которых сосредоточены на поиске эманационных предвестников землетрясений [Kuo, 2014; Virk, 1996; Fleischer, 1981; Fleischer, Mogro-Campero, 1985; Woith, 2015]. Благодаря радиоактивным свойствам, радон является наиболее удобным для исследований данного типа, так как уровень его объемной активности (Q) достаточно легко фиксируется в окружающей среде. Параметр Q напрямую зависит от площади свободной поверхности эманирующих горных пород, которая, в свою очередь, меняется при вариациях напряженного состояния, обусловленных колебаниями атмосферного давления и степенью геодинамической активности.

На территории Байкальской рифтовой зоны, отличающейся сложной структурной обстановкой и повышенной сейсмичностью, исследования пространственно-временных флуктуаций радонового поля начаты в 2012 г. К настоящему моменту проведены площадная радиометрическая съемка естественных водопроявлений [Seminsky K.Zh., Seminsky A.K., 2019] и эманационный мониторинг восьми источников подземных вод, располагающихся на территории Южного Приангарья. Работы, направленные на выявление взаимосвязи сейсмической активности с колебаниями объемной 
активности радона в подземных водах, начаты на данной территории в 2019 г. [Seminsky A.K., Seminsky K.Zh., 2020, 2021]. Полученные закономерности основываются на результатах анализа рядов девятилетнего мониторинга (частота опробования дважды в месяц), а также детальных (ежедневных) наблюдений за параметром Q в одном из источников, входящих в опорную сеть.

По результатам предварительных исследований установлено, что сейсмическая активность в пределах Байкальского региона оказывает слабое прямое влияние на параметр Q в подземных водах Южного Приангарья, изменение которого проявляется с задержкой во времени после землетрясения. Низкий уровень выявленной статистической связи может быть обусловлен двумя главными факторами: во-первых, сравнительно низкой сейсмической активностью в период проведения режимных наблюдений; во-вторых, переменной частотой и неравномерностью пространственного распределения очагов происходящих землетрясений. Низкая эффективность статистических методов анализа делает необходимыми создание длительных рядов детального мониторинга и применение выборочного подхода к выборке землетрясений, произошедших на исследуемой территории за период эманационного мониторинга.

Целью данной работы было проанализировать вариации объемной активности радона в подземных водах Байкальского региона за 2021 г., а также исследовать отклик эманационного поля на наиболее значимые землетрясения, произошедшие в пределах данной территории за тот же период, включая пять сейсмических событий с магнитудой больше 5.

Достижение намеченной цели осуществлялось решением следующих задач: во-первых, организации детальных режимных наблюдений за параметром Q в подземных водах исследуемого региона; во-вторых, анализа вариаций радона в опробуемом источнике; в-третьих, обоснования выборки наиболее значимых землетрясений за 2021 г. и анализа пространственного положения их очагов относительно пункта опробования; в-четвертых, выявления и типизации эманационных откликов поля радона на землетрясения, вошедшие в составленную выборку.

\section{2. МЕТОДИКА}

Решение первой задачи заключалось в проведении детальных режимных наблюдений. Для этого из числа опробуемых дважды в месяц водосточников выбран один, характеризующийся средней, относительно остальных, концентрацией радона. Особенность заключается в том, что по абсолютным значениям параметра Q характерным для изучаемой территории, выбранный источник относится к группе аномальных [Seminsky K.Zh., Seminsky A.K., 2019], что позволяет наблюдать отчетливые колебания измеряемого параметра во времени. Кроме того, выбор данного источника для детального мониторинга определяется его расположением в зоне влияния крупных разрывных структур Байкальского рифта (юго-восточный сегмент крупного Ангарского разлома). Отбор проб воды производился один раз в сутки. В качестве измерительного оборудования применялся радиометр PРA-01M-03, входящий в перечень приборов государственного реестра (номер в базе 21365-01). Радиометр характеризуется пределом относительной погрешности $\pm 30 \%$.

Длительность рядов данных, сформированных в ходе режимного опробования водоисточника, дренирующего крупный Ангарский разлом, превышает 600 дней. Важно отметить непрерывность ежесуточного мониторинга, что имеет существенное значение для исследования закономерностей временных вариаций поля радона и повышает достоверность его результатов.

\section{3. РЕЗУЛЬТАТЫ}

Для решения второй задачи были построены графики колебаний объемной активности радона в исследуемом источнике за весь период детального мониторинга параметра Q (рис. 1). За 2021 г. объемная

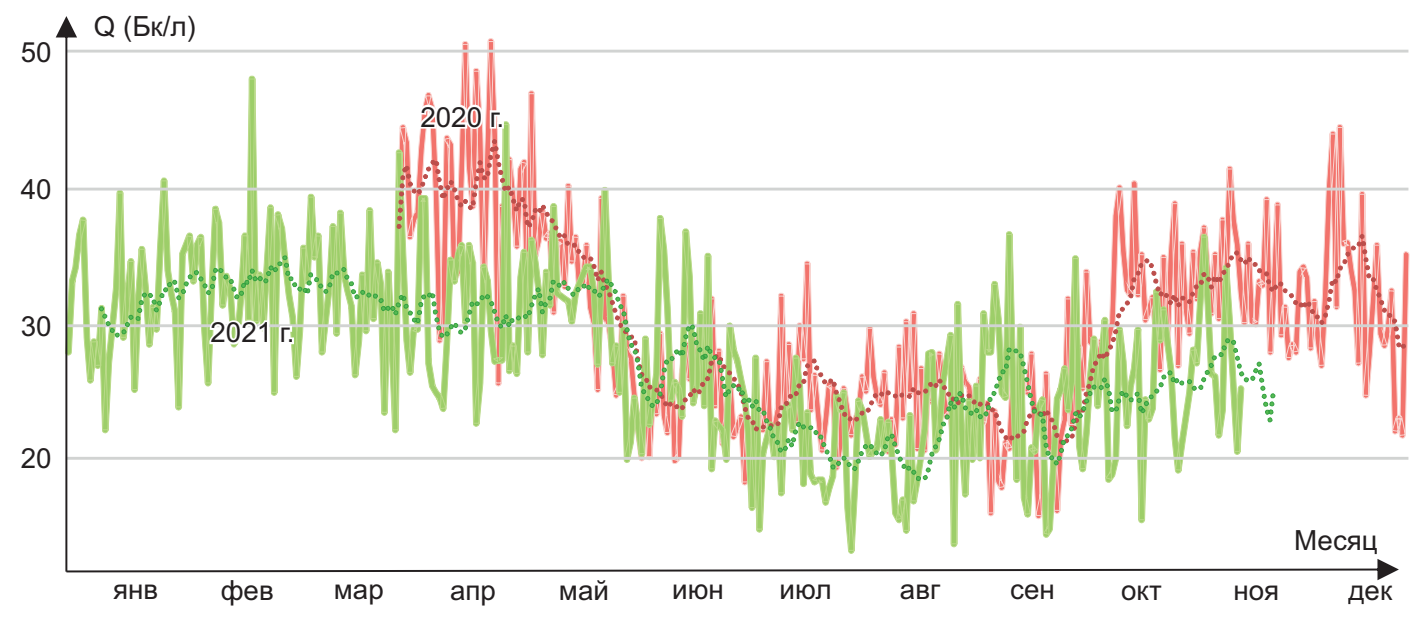

Рис. 1. Графики данных мониторинга радона за 2020 и 2021 гг. (пунктиром выделены линии тренда).

Fig. 1. Radon monitoring data curves for 2020 and 2021 (the dot shows three trend lines). 
активность радона колебалась в пределах от 13.2 до 48.4 Бк/л с максимальными значениями в марте и апреле (т.е. в конце меженного периода), а минимальными - с июля по сентябрь. Среднегодовой показатель составил 26 Бк/л, что на $14 \%$ ниже данного значения в 2020 г. Снижение средних значений обусловлено, вероятнее всего, бо́льшим, по сравнению с предыдущими годами, количеством атмосферных осадков, фильтрация которых с поверхности приводит к разбавлению подземных вод. Среднесуточные колебания параметра Q за прошедший год, напротив, составили 4.5 Бк/л, тогда как в 2020 г. данный показатель отмечался на уровне 4.4 Бк/л. Также увеличилась амплитуда максимальной суточной флуктуации объемной активности радона, в 2020 г. она составила 18 Бк/л, в 2021 г. - 21 Бк/л. Данная особенность по-видимому, обусловлена повышением уровня сейсмической активности на рассматриваемой территории в течение анализируемого интервала времени: количество землетрясений в 2021 г. в несколько раз превышает соответствующий показатель 2020 г. Закономерности, выявленные в результате анализа рядов мониторинга параметра Q за 2021 г., обнаруживают удовлетворительную сходимость с материалами, полученными на ранних этапах исследования, а присутствующие незначительные отличия объясняются в одном случае экзогенными (количество атмосферных осадков), а в другом - эндогенными (сейсмичность) факторами.

Для решения третьей задачи исследования из списка сейсмических событий, зафиксированных в период детального мониторинга, выбирались землетрясения, способные вызвать заметные колебания эманационного поля. Всего за 2021 г. на исследуемой территории произошло 541 событие с энергетическим классом (K) от 8.8 до 15.7 и магнитудой (M) от 3.2 до 6.8 соответственно (по данным Байкальского филиала геофизической службы PAH, http://seis-bykl.ru/). Более чем в 90 \% случаев (501 землетрясение) магнитуда не превышала 4. Реакция эманационного поля на такие события, согласно имеющимся данным [Seminsky A.K., Seminsky K.Zh., 2020], описывается умеренной прямой корреляционной зависимостью и проявляется во временных рядах объемной активности радона примерно через четверо суток после самого события. Следовательно, для углубленного изучения реакции эманационного поля необходимо отобрать землетрясения с $\mathrm{M} \geq 4$. За 11 месяцев мониторинга произошло 40 подобных событий. Подавляющее количество их эпицентров расположено в пределах Байкальской рифтовой зоны и находится на расстоянии от 155 до 1056 км от опробуемого источника подземных вод (рис. 2, а).

Для оценки степени воздействия, оказываемого сейсмическими событиями на эманационное поле, необходимо оценить радиус зоны влияния каждого из произошедших землетрясений. К этой зоне относится область, в пределах которой при подготовке сейсмического события возможна фиксация предвестниковых (в т.ч. эманационных [Hirok et al., 2011]) эффектов.
Существует несколько формул расчета данного параметра, из которых обычно используются следующие:
$R=10^{0.43 M}$
(1) [Dobrovolsky et al., 1979];
$R=10^{(M+0.43)}$
(2) [Hauksson, 1981];
$R=10^{0.38 M+0.33}$
(3) [Rikitake, 1988];
$R=10^{0.5 M-0.27}$
(4) [Morgounov, Malzev, 2007].

Согласно представленным формулам, магнитуда произошедшего землетрясения (M) является частью степенного показателя десятикилометрового радиуса (R) зоны влияния. По результатам произведенных расчетов установлено, что пункт опробования находился в пределах радиуса влияния двух сейсмических событий; одно землетрясение зафиксировано на дистанции 1.5R. Еще четыре события произошли на расстоянии от 1.5 до 3.0R от опробуемого источника. Расстояние до эпицентров оставшихся 33 событий более чем в три раза превысило величину расчетного радиуса влияния. Таким образом, рассматриваемая выборка является представительной для исследования влияния, оказываемого степенью удаленности и магнитудой землетрясения на характер эманационного отклика.

Решение четвертой задачи заключалось в исследовании графика вариаций параметра Q для выявления и типизации откликов эманационного поля на наиболее значимые землетрясения. Выявлено три основных типа таких откликов, отличающихся характером и амплитудой флуктуаций, а также моментом ее проявления относительно момента землетрясения.

Первый из них (рис. 2, б, I) проявляется в виде незначительных пиков на графике параметра Q с запаздыванием в пределах четырех суток после сейсмического события, т.е. демонстрирует сходство с реакцией на сейсмические события с $\mathrm{M}<4$, которые, как менее значимые, не вошли в анализируемую выборку. Подобный отклик зафиксирован при 33 землетрясениях, очаги которых располагались в северо-восточном сегменте Байкальской рифтовой зоны или находились в Забайкалье на значительном удалении (200-300 км) от ее оси.

Второй тип реакции эманационного поля отмечается в течение первых суток после сейсмического события в виде снижения параметра Q на 15-20 \% относительно среднего уровня для данного сезона года (рис. 2, б, II). Отклик второго типа был отмечен после четырех землетрясений, очаги которых расположены в осевой части Байкальского рифта.

Третий тип эманационного отклика, характеризующийся снижением объемной активности радона, отмечается за сутки перед событием, т.е. отражает реакцию поля не на само землетрясение, а на процесс его подготовки (рис. 2, б, III). Подобный предвестниковый эффект был отмечен перед тремя землетрясениями. В их число вошло самое сильное за последние 10 лет на исследуемой территории Хубсугульское (11.01.2021) землетрясение, магнитуда которого составила 6.8 (http:// seis-bykl.ru/). 
Группировка сейсмических событий по удаленности от пункта опробования (относительно радиусов их влияния), за редким исключением, совпадает с группировкой событий по типу наблюдаемого отклика и времени его фиксации (рис. 2, а). Так, эпицентры землетрясений, вызвавших отклик первого типа, располагались на расстоянии >3R от опробуемого водоисточника. Для событий с откликом второго типа это расстояние составляло 1.5-3.0R. Реакция эманационного поля третьего типа была зафиксирована при подготовке землетрясений, для которых радиус влияния покрывал опробуемый водоисточник.

Исключение составили два сейсмических события, первое из которых произошло 21.02.2021 г. с M=5.1 на расстоянии 2.4R от пункта мониторинга, второе 03.05.2021 г. с M=6.1 на расстоянии 0.5R. Согласно полученным закономерностям, данные события должны вызывать в опробуемом источнике реакцию второго и третьего типа соответственно. Эманационные аномалии присутствовали в рядах данных и были зафиксированы во временных пределах, согласующихся с разработанными сценариями соответствующих откликов, однако характер аномалий на кривых графика имел нестандартный вид, а именно: в обоих случаях присутствовал заметный всплеск эманационной активности с последующим снижением, которое, в свою очередь, уже вписывалось в разработанную типизацию. Подобные флуктуации эманационного поля могут

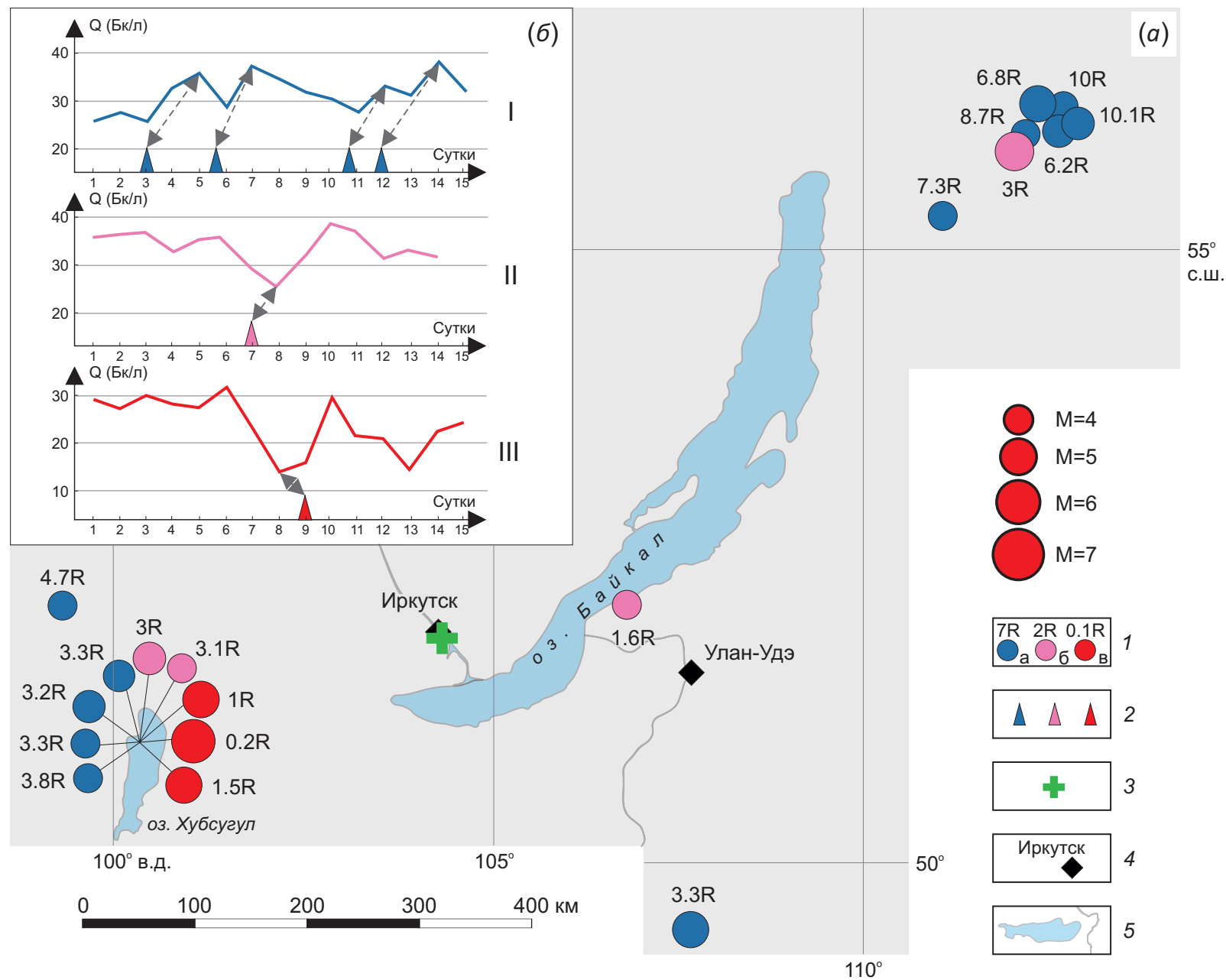

Рис. 2. Схема расположения очагов землетрясений и опорного пункта ежедневного опробования $(a)$ и примеры типов реакции эманационного поля на наиболее значимые землетрясения в пределах Байкальского региона (б).

1 - очаги изученных сейсмических событий, индексы которых обозначают расстояние от пункта мониторинга до эпицентра землетрясения в радиусах области его влияния (цветом показан тип реакции, зафиксированный в пункте мониторинга: а реакция первого типа, б - реакция второго типа, в - реакция третьего типа); 2 - момент сейсмических событий на графиках вариаций параметра Q; 3 - пункт ежедневного мониторинга Q; 4 - крупные населенные пункты; 5 - гидросеть.

Fig. 2. A map of earthquake sources and daily sampling points (a); examples of the types of the emanation field response to the most significant earthquakes in the Baikal region (б).

1 - sources of the studied seismic events whose indices show the distance from the monitoring site to the epicenter of an earthquake in the radiuses of its area of influence (the color shows the type of response recorded at the monitoring site: a - first-type response; б - second-type response; в - third-type response); 2 - a moment of seismic events on Q-parameter variation curves; 3 - a daily Q-monitoring site; 4 - large settlements; 5 - drainage system. 
быть вызваны рядом причин, установление которых требует дополнительных, целенаправленных исследований. Одним из вероятных факторов, вызвавших нехарактерную реакцию радонового поля, является влияние сейсмических событий, произошедших далеко за пределами Байкальского региона. Подобные эффекты ранее фиксировались в Байкальском регионе при изучении временных вариаций параметра Q в почвах [Seminsky, Bobrov, 2013].

\section{4. ЗАКЛЮЧЕНИЕ}

Проведенное исследование позволило получить следующие основные результаты.

1. В ходе опробования водоисточника, дренирующего в Южном Приангарье крупный Ангарский разлом, получены длинные ряды мониторинговых данных. Временной интервал непрерывного ежесуточного мониторинга превышает 600 дней.

2. Анализ данных за 2021 г. показал, что объемная активность радона колебалась в пределах от 13.2 до 48.4 Бк/л со среднегодовым показателем 26 Бк/л. Среднесуточное колебание составило 4.5 Бк/л, а амплитуда максимальной суточной флуктуации - 21 Бк/л. В целом, полученные закономерности проявляют удовлетворительную сходимость с результатами подобного анализа, проведенного на ранних этапах исследования, за исключением некоторых незначительных отличий, которые объясняются влиянием экзогенных и эндогенных факторов.

3. Из числа произошедших за время ежедневного мониторинга землетрясений выбраны 40 наиболее значимых (M $\geq 4)$, для которых рассчитывались радиусы областей влияния. В трех случаях пункт опробования входил в эту область или находился от нее в непосредственной близости, в четырех случаях фактическая дистанция от пункта мониторинга до эпицентра в полтора-три раза превышала расчетный радиус, в оставшихся 33 случаях это расстояние было превышено более чем в три раза.

4. Анализ графиков мониторинга параметра Q показал, что большинство землетрясений, происходящих в пределах Байкальской рифтовой зоны, вызывает заметные колебания эманационного поля. Выявлено три типа эманационного отклика на сейсмические события, один из которых может быть зафиксирован перед землетрясением, т.е. является прогностическим признаком. Необходимо отметить, что в число сейсмических событий, демонстрирующих такой эффект, вошло Хубсугульское землетрясение, являющееся наиболее сильным на территории исследования за последние десять лет. Группировка по удаленности очага от пункта опробования относительно радиуса влияния произошедшего события практически совпадает с группировкой землетрясений по времени регистрации и типу фиксируемых откликов. Таким образом, колебания эманационного поля распространяются от области подготовки землетрясения на значительные расстояния с постепенным затуханием, а момент фиксации отклика и вид проявившейся на графике аномалии зависят от энергии готовящегося события, а также от расстояния между эпицентром землетрясения и пунктом опробования. В целом, выявление эманационных предвестниковых эффектов перед сильными землетрясениями на территории Байкальского региона возможно с учетом двух факторов: во-первых, достаточной силы готовящегося землетрясения; во-вторых, расположения пункта опробования в пределах радиуса области влияния данного события.

\section{5. КОНФЛИКТ ИНТЕРЕСОВ / CONFLICT OF INTERESTS}

Автор заявляет об отсутствии у него конфликта интересов. Автор прочитал рукопись и согласен с опубликованной версией.

The author have no conflicts of interest to declare. The author have read and agreed to the published version of the manuscript.

\section{6. ЛИТЕРАТУРА / REFERENCES}

Dobrovolsky I.P., Zubkov S.I., Miachkin V.I., 1979. Estimation of the Size of Earthquake Preparation Zones. Pure and Applied Geophysics 117, 1025-1044. https://doi.org/10. 1007 /BF00876083.

Fleischer R.L., 1981. Dislocation Model for Radon Response to Distant Earthquakes. Geophysical Research Letters 8 (5), 477-480. https://doi.org/10.1029/GL008i00 5 p00477.

Fleischer R.L., Mogro-Campero A., 1985. Association of Subsurface Radon Changes in Alaska and the Northeastern United States with Earthquakes. Geochimica et Cosmochimica Acta 49 (4), 1061-1071. https://doi.org/10.1016/00 16-7037(85)90319-9.

Hauksson E., 1981. Radon Content of Groundwater as an Earthquake Precursor: Evaluation of Worldwide Data and Physical Basis. Journal of Geophysical Research: Solid Earth 86 (B10), 9397-9410. https://doi.org/10.1029/JB0 86iB10p09397.

Hirok C., Waseem B, Naseer I., Rakaesh K., Debasis G., Prasanta S., Bikash S., 2011. Long Range Gas-Geochemical Anomalies of a Remote Earthquake Recorded Simultaneously at Distant Monitoring Stations in India. Geochemical Journal 45, 137-156. https://doi.org/10.2343/geochemj. 1.0109.

Kuo T., 2014. Correlating Precursory Declines in Groundwater Radon with Earthquake Magnitude. Groundwater 52 (2), 217-224. https://doi.org/10.1111/gwat.12049.

Morgounov V.A., Malzev S.A., 2007. A Multiple Fracture Model of Pre-Seismic Electromagnetic Phenomena. Tectonophysics 431 (1-4), 61-72. https://doi.org/10.1016/j. tecto.2006.05.030.

Rikitake T., 1988. Earthquake Prediction: An Empirical Approach. Tectonophysics 148 (3-4), 195-210. https:// doi.org/10.1016/0040-1951(88)90128-X.

Seminsky A.K., Seminsky K.Zh., 2020. Preliminary Results of the Study of the Relationship of Seismic Activity with the Concentration of Radon in Groundwater in the 
Southern Angara Region. The Bulletin of Irkutsk State University. Series Earth Sciences 33, 100-111 (in Russian) [Ceминский А.К., Семинский К.Ж. Предварительные результаты исследования взаимосвязи сейсмической активности с концентрацией радона в подземных водах Южного Приангарья // Известия Иркутского государственного университета. Серия Науки о Земле. 2020. T. 33. C. 100-111]. https://doi.org/10.26516/2073-3402. 2020.33.100.

Seminsky A.K., Seminsky K.Zh., 2021. Variations in Radon Activity in the Groundwater of the Southern Baikal Region: Emanation Response of Earthquakes Doklady Earth Sciences 499, 661-665. https://doi.org/10.1134/S10283 34X21080134.

Seminsky K.Zh., Bobrov A.A., 2013. The First Results of Studies of Temporary Variations in Soilradon Activity of Faults in Western Pribaikalie. Geodynamics \& Tectonophysics
4 (1), 1-12 (in Russian) [Семинский К.Ж., Бобров А.А. Первые результаты исследований временных вариаций эманационной активности разломов Западного Прибайкалья // Геодинамика и тектонофизика. 2013. T. 4. № 1. C. 1-12]. https://doi.org/10.5800/GT-2013-41-0088.

Seminsky K.Zh., Seminsky A.K., 2019. Radon Concentration in Groundwater Sources of the Baikal Region (East Siberia, Russia). Applied Geochemistry 111, 104446. https:// doi.org/10.1016/j.apgeochem.2019.104446.

Virk H.S., 1996. A Critique of Empirical Scaling Relationship between Earthquake Magnitude, Epicentral Distance and Precursor Time for Interpretation of Radon Data. Journal of Earthquake Prediction Research 5 (4), 547-583.

Woith H., 2015. Radon Earthquake Precursor: A Short Review. The European Physical Journal Special Topics 224, 611-627. https://doi.org/10.1140/epjst/e2015-02395-9. 